\title{
A SUBJETIVIDADE COMO UMA PROPOSTA DE ABORDAGEM PARA PENSAR NA AVALIAÇÃO DOS ALUNOS CONSIDERADOS COMO DIFÍCEIS: UM MÉTODO DA PSICANÁLISE APLICADA PARA PENSAR O MAL-ESTAR NA EDUCAÇÃO
}

\section{ARTIGO ORIGINAL}

CURVELO, Carmem Lana Pereira ${ }^{1}$

CURVELO, Carmem Lana Pereira. A subjetividade como uma proposta de abordagem para pensar na avaliação dos alunos considerados como difíceis: um método da psicanálise aplicada para pensar o mal-estar na educação. Revista Científica Multidisciplinar Núcleo do Conhecimento. Ano 04, Ed. 05, Vol. 03, pp. 114-128 Maio de 2019. ISSN: 2448-0959

\section{RESUMO}

O presente artigo apresenta os resultados da aplicação de uma metodologia que foi desenvolvida a partir de uma experiência interdisciplinar para a investigação da "criança-problema". Esta metodologia consiste em mostrar um estudo sobre a construção clínico-psicanalítica de cada caso de aluno, tendo-se como foco aqueles alunos considerados como um verdadeiro desafio para a equipe pedagógica da escola, em função, não apenas das dificuldades de aprendizagem em termos de leitura e da escrita, mas também considerou-se outros aspectos como a presença de um comportamento perturbador e inadequado junto aos professores e colegas de sala. A pesquisa foi realizada em escolas das redes pública e privada de Belo horizonte - Minas Gerais. A partir da análise dos dados coletados percebeu-se a necessidade de pensar nesses alunos por meio da metodologia defendida, pois ela é capaz de fazer com que o corpo docente da instituição, após as devidas análises, olhe para esses alunos de forma mais empática para melhor compreender essa defasagem

\footnotetext{
${ }^{1}$ Mestre Em Ciências Empresariais, Com Mba Em Ensino Superior E Controladoria E Perícia Judicial.
} 
na aprendizagem e no comportamento. Os professores partem do princípio de que para que se conviva em harmonia, é preciso que os acontecimentos vividos na sala de aula sejam ressignificados a partir da própria história da criança. A análise dessas interações, por sua vez, fornece estratégias para que o trabalho cotidiano junto aos alunos seja bem feito. É uma metodologia que buscou investigar como a subjetividade pode contribuir no processo de avaliação da dificuldade, evitando-se a tendência de excluir os alunos por conta da "indisciplina".

Palavras-chave: crianças-problema, problemas de aprendizagem, subjetividade, inclusão, psicanálise

\section{INTRODUÇÃO}

Inicialmente é necessário situar que este artigo nasceu a partir do projeto de pesquisa situado na área da Psicanálise e Educação intitulado "Praticas escolares de atendimento para pensar a "criança problema": desafio da inclusão", cujo objetivo era o de aplicar esta metodologia de em um estudo de caso interdisciplinar - caracterizado como diagnóstico, clínico e pedagógico. Pretendeu-se observar as dificuldades de aprendizagem e os distúrbios de comportamento. Esta pesquisa foi realizada em uma Escola Estadual de ensino especial, localizada na cidade de Belo Horizonte/Minas Gerais, e teve início a partir de um convite feito pela orientadora pedagógica da Escola. Desejava-se que fossem realizados estudos de caso tendo como objeto alguns alunos considerados verdadeiros desafios para a equipe pedagógica da escola. Tratavam-se de crianças que apresentavam não apenas dificuldades de aprendizagem na leitura e na escrita, mas também um comportamento perturbador e inadequado junto aos docentes e aos colegas, para não citar as frequentes crises de agitação marcadas por violência, que impunham, na maioria das vezes, intervenção psiquiátrica de urgência e, e, por vezes, registrou-se casos em que houve intervenção policial.

Dentro deste eixo de investigação, algumas questões tomaram forma sobretudo a seguinte: o que fazer com estes alunos que são contabilizados como uma "criançaproblema" para amenizar o fracasso escolar? A demanda inicial era que se realizasse 
uma investigação aprofundada destes casos, por meio de um diagnóstico clínicopedagógico para se analisar as dificuldades de aprendizagem das crianças em dois pianos distintos: um cognitivo e outro relativo a economia subjetiva do aluno (Santiago, 2005). Observou-se que esses alunos difíceis já tinham sido objeto de estudo, avaliação e diagnóstico. Além de terem passado por inúmeras investigações, essas crianças recebiam todo tipo de atenção especializada: reeducação pedagógica, fonoaudiológica, participavam de oficinas terapêuticas, faziam acompanhamento psicológico assim como o controle psiquiátrico. Essa atenção estendia-se, também, aos pais, por meio de programas de orientação e apoio a família.

Apesar disso, uma nova demanda de estudo de caso foi feita pela orientadora educacional, mas, desta vez, apoiada sobre a constatação da ineficácia dessas diversas intervenções realizadas junto aquelas crianças. Os profissionais envolvidos defrontavam-se, repetidamente, com o limite de suas especialidades. Mesmo que, no curso dos anos, eles não tenham deixado de dar continuidade a formação profissional, buscando o contato contínuo com novas abordagens teóricas que eram lançadas, de tempos em tempos, no mercado do saber, muitos foram os desafios para lidar com essas crianças. O entusiasmo inicial a partir do contato com outras dimensões de um problema que ocasionava, possivelmente, no fracasso escolar, bem como as suas propostas de intervenção re-educativa ou psicoterápica, acabavam dando lugar a convicção de que alguns casos permaneceriam como enigmas indecifráveis.

O que fazer com o aluno que escreve, mas não sabe ler? Como avaliar aquele que, em casa, fala, mas, na escola, nunca pronunciou sequer uma sílaba, não responde a nenhuma demanda do professor? Como garantir a inclusão daquele que, diante da menor frustração, sai quebrando a escola? Estas são algumas das questões, que foram reabertas a partir da aposta dos profissionais da referida escola na contribuição da psicanalise a educação. Adotou-se esta perspectiva para pensar onde se localizava o mal-estar da educação. Esta contribuição despertou nos interessados a necessidade de entender a particularidade do sujeito, para tanto, esses investigadores caminharam para além das ofertas identificadoras propostas pelas diversas abordagens teóricas. 
O contato inicial com essa questão foi feito por meio do trabalho de tese intitulado "Sobre a inibição intelectual na psicanalise" (Santiago, 2005), pois este discute as formas de se diagnosticar os problemas de aprendizagem e a maneira pela qual o aluno pode ser identificado como portador de um déficit. Devido a própria natureza do processo de avaliação utilizado, esses diagnósticos desconhecem a necessidade da criança de valer-se do sentido dos conteúdos escolares para inscrever sua particularidade e, mesmo, para se aperceber, ou seja, sentir esses conteúdos. Não é possível afirmar que toda dificuldade de aprendizagem se manifesta a partir de um sintoma, mas para afirmar isso é preciso investigar o processo de formação do inconsciente.

Ao nosso ver, o desconhecimento da dimensão subjetiva acarreta na dificuldade de aprendizagem o que, muitas vezes, inviabiliza qualquer tentativa de intervenção terapêutica, produzindo-se, dessa forma, efeitos indesejados tais como a segregação e exclusão do aluno do ensino regular. Sabe-se o quanto as estratégias terapêuticas para garantir o acesso do sujeito a um desempenho estipulado pelas exigências da norma acabam culminando na impotência: não é raro que a permanência de uma dificuldade de aprendizagem dure toda a vida escolar de uma criança - e isso, quando ela não interrompe sua trajetória escolar, devido a persistência do fracasso. Essa constatação levou a proposição de um procedimento diagnóstico, designado clínicopedagógico, cujo objetivo fora a identificação do estatuto da dificuldade em duas esferas distintas: uma cognitiva e outra relativa a economia subjetiva do aluno.

A avaliação cognitiva baseia-se na investigação do conhecimento da criança, no plano estrito do seu domínio acerca dos fundamentos teóricos absolutamente indispensáveis para a superação de erros de conteúdo. Para além do domínio teórico dos conteúdos, os impasses de aprendizagem são indicativos de sintomas de inibição intelectual. Nessa perspectiva, busca-se esclarecer a trajetória intelectual em que a criança desenvolve, a partir da solução de uma tarefa, até o ponto preciso onde se localiza seu impasse subjetivo, a articulação do conteúdo.

A metodologia do diagnóstico clínico-pedagógico inspira-se em duas abordagens teóricas distintas exploradas aqui, de maneira complementar. O método clínico 
proposto pela abordagem cognitivista para investigar as hipóteses conceituais presentes na produção dos erros pelo aprendiz, tem como escopo a exploração do método, pois é um processo fundamental para a desconstrução e superação dos mesmos. Por outro lado, utiliza-se a metodologia de entrevista ao paciente instrumento central de conhecimento da psicopatologia psiquiátrica - que, no domínio da prática psicanalítica, investiga como determinados sintomas aparecem no discurso do paciente.

Assim, a criança é interrogada sobre sua dificuldade escolar, tal como se interroga um paciente a respeito de seus sintomas. Deve-se notar que essa atitude de investigação apenas é possível quando o entrevistador se coloca na posição de não saber diante do outro, despojando-se do lugar tentador de mestre, que o adulto, normalmente, tende a adotar frente a uma criança. O recurso de escutar o que a própria criança tem a dizer sobre a sua dificuldade, ou seja, de levar em consideração o que o sujeito sabe a respeito do que the acontece, possibilita não apenas a elucidação de elementos da subjetividade ou de sentido inconsciente, mas acresce o mínimo de significação que o conteúdo escolar deve ter, como também pensa-se em um método de intervenção re-educativo particularizado.

Em suma, o diagnóstico clínico-pedagógico visa conciliar a investigação dos processos da consciência com o pensamento conceitual, pois ambos passam por um processo de desenvolvimento de conhecimento no campo dos processos de aprendizado da língua escrita. Conforme já dizia Jean Piaget (Ferreiro e Teberosky, 1985/1991; Kamii, 1989/1992; Oliveira \& Nascimento, 1990; Oliveira, 1992; Alvarenga, 1993; Macedo, 1994), a investigação psicanalítica dos processos primordiais inconscientes, deve ser subjacente a produção de erros na construção do conhecimento. Trata-se não apenas de um instrumento de investigação, mas também de intervenção junto a crianças que apresentam distúrbios de aprendizagem. Em outros termos, o diagnóstico clínico-pedagógico é uma proposta de tratamento para dificuldades escolares que deve ser realizado no interior da instituição escolar, visando evitar a exclusão da criança. 


\section{MATERIAIS E MÉTODOS}

A utilização dessa proposta diagnóstica para a realização de um estudo de casos sobre os alunos do ensino especial revelou alguns limites e, como tal, exigiu a introdução de algumas modificações, tornando-se necessária a proposição de procedimentos complementares, em função das particularidades das dificuldades do(a) aluno(a), como, por exemplo, a impossibilidade de contato direto com alguns deles. Por conta da falta de acesso a determinados perfis de alunos, os critérios precisaram ser repensados assim como os possíveis participantes colaboradores do estudo. Como é uma metodologia que se ocupa em analisar a consciência humana, um dos maiores desafios foi interpretar as particularidades/individualidades.

Os profissionais envolvidos, valendo-se de seus conhecimentos específicos, optaram por um tipo de estudo de caso abrangente, que incluísse um estudo acerca da vida escolar da criança, assim defendeu-se a necessidade de uma análise que se preocupassem em entender a língua escrita e falada, pensando-se, sempre, no ambiente da sala de aula (Castanheira, 2004). Para isso, foi feito um levantamento do histórico para se recuperar registros psiquiátricos e psicológicos desses alunos, para a análise deste quadro clínico. Buscou-se analisar como esses se comportavam em sessões de entrevistas orientados pelo aporte da psicanálise, pois ela pensa na formação do sintoma, nas particularidades do sujeito e na sua estrutura psíquica (Santiago, 2005). Assim, o instrumento de avaliação clinico-pedagógica passou a ser composto de três etapas: histórico do caso, avaliação pedagógica e avaliação clínica.

O objetivo da primeira etapa - histórico do caso - foi o estabelecimento de um perfil de aluno a partir das informações fornecidas a respeito do mesmo por parte dos profissionais da Escola. Busca-se delinear:

1) O que é dito a respeito do aluno;

2) Quais os elementos teóricos que se encontram incorporados nesse discurso, construído na tentativa de explicar o problema do aluno; e 
3) Que informações desse discurso são contraditórias ou vagas.

Pretendeu-se destacar, a partir do conjunto das informações recolhidas, o que circula entre os educadores, os aspectos mais relevantes que passam a identificar o aluno no espaço escolar e, a partir desses dados, verificou-se, também, se tais ofertas identificatórias são oriundas daquilo que se sabe a respeito de sua história familiar, dos antecedentes clínicos, da trajetória psiquiátrica, com intuito de se avaliar se esses fatores tomam forma seu comportamento na escola ou se referem a evolução no plano pedagógico. Ainda nessa primeira etapa, realizou-se um estudo dos dados registrados no prontuário escolar, buscando-se estabelecer um segundo perfil de aluno, cujo objetivo fora procurar e entender o motivo do encaminhamento deste para a escola de ensino especial. As duas questões que norteiam este estudo são:

1) $O$ que foi determinante para a identificação do aluno como "portador de necessidades especiais"?

2) Existe uma avaliação do aluno no plano das aprendizagens escolares ou sobressai a queixa de distúrbio de comportamento, indicativa de uma dificuldade no plano do sintoma?

Em seguida, prosseguiu-se para o entendimento da história clínica do aluno a partir da análise de seu prontuário psiquiátrico, em que se registraram dados acerca do acompanhamento relacionado ao tratamento quimioterápico e/ou terapêutico. A segunda etapa - avaliação pedagógica - prevê uma série de observações acerca do desempenho do aluno em sala de aula e no ambiente escolar, considerando, para a avaliação, os seguintes aspectos: interação do aluno com o professor, com os colegas e com a aprendizagem e a interação do professor com o aluno, com a turma e com as práticas educativas na sala de aula.

Buscando-se não evidenciar o alvo de sua observação, o pesquisador foi apresentado a turma, este, por sua vez, enunciou o seu propósito de maneira geral, e, posteriormente, participou das atividades planejadas pelo docente na sala de aula interagindo, ativamente, com todos os alunos. A produção pedagógica do aluno 
problema foi avaliada entre as demais, assim como as formas de avaliação propostas. $O$ docente e entrevistado buscaram esclarecer esses aspectos. Nos casos em que isso parece justificado, propôs-se, ainda, uma avaliação pedagógica individual do aluno, visando situar o nível cognitivo em que esse se encontrava para trabalhar os erros recorrentes na perspectiva de uma desconstrução dos mesmos.

\section{RESULTADOS E DISCUSSÃO}

A partir da realização de uma avaliação clínica construída a partir análise de entrevistas que tomaram como modelo o procedimento da "apresentação de pacientes", buscou-se interpretar, junto a ela, as outras etapas a partir do conteúdo gravado e transcrito com o consentimento do entrevistado, para se proceder, posteriormente, para a realização de uma análise mais profunda. O ponto de partida desta entrevista clínica busca interrogar, afetivamente, a criança acerca de seu sintoma, no caso, a dificuldade escolar a partir da proposição de algumas questões: Porque foi encaminhado para o ensino especial ou para tratamento? Qual é sua dificuldade escolar? Em que momento surgiu? Como evoluiu?

O que se busca entender é como se configura o saber do aluno a respeito do que the ocorre, ou seja, daquilo que constitui um mal-estar. Nessa etapa, os pais ou responsáveis podem funcionar uma fonte que contém a informação principal acerca dos entrevistados, assim eles foram consultados apenas para se poder se situar, pois eles apresentaram o histórico do desenvolvimento geral da criança, com as respostas desta ao que the foi ofertado, no plano das relações familiares a partir de desejos, ideais e modos de satisfação mais característicos do grupo familiar.

Com base nas informações colhidas durante esse processo diagnóstico, procede-se a construção do caso. Do conjunto dos fatos, situados inicialmente em uma sequência diacrônica, apenas alguns vão se destacar como respostas sintomáticas do sujeito. Esta leitura e feita por retroação, buscando-se localizar a produção do sintoma ou da dificuldade da criança no eixo sincrónico, tal como representado abaixo: 


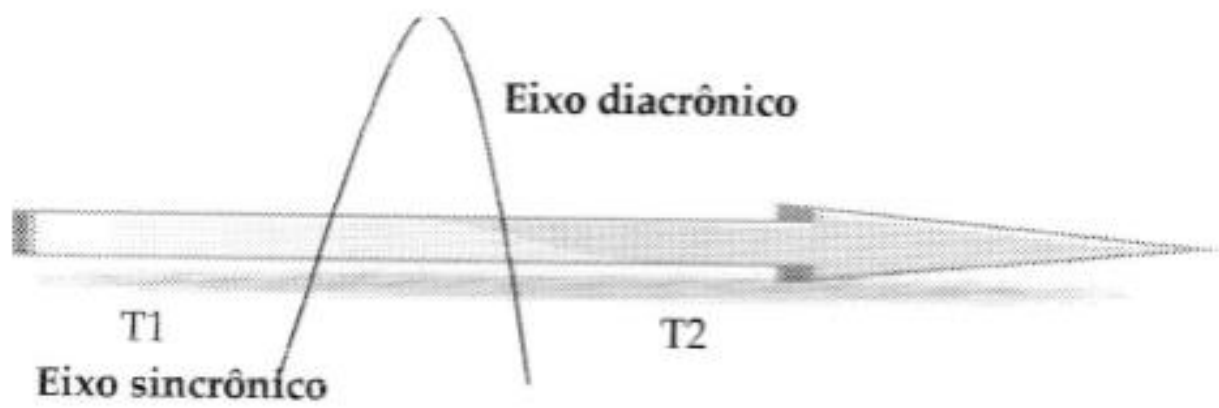

É por meio desta relação retroativa que a psicánalise situa os acontecimentos traumáticos de encontros do sujeito com o real e, por outro lado, evidencia o efeito simbólico deste encontro, personificando o sintoma. Para a psicanálise, portanto, não se pode prever que um acontecimento $X$, vivido em um tempo - T1 terá por consequência, em um tempo futuro - T2 - a produção de um sintoma $X$. O tempo do surgimento do sintoma é sempre um T2, que produz um efeito de significação sobre o trauma vivido no T1. Esse esquema - em que uma significação apenas tem lugar aposteriori, por retração - na obra de Jacques Lacan (1936/2001), possui um valor polivalente. Foi utilizado não apenas para relacionar o trauma a produção do sintoma, mas também para situar a transferência, formalizar o desejo do sujeito na sua relação com o outro, com o analista e com o saber.

Em última análise, esse esquema se presta a diversas formalidades e constituindo, dessa forma, a célula básica da relação analítica, para expor a própria concepção do inconsciente. A lógica desse esquema norteia a construção do caso do aluno a partir de sua produção sintomática que tem permitido, inclusive, uma definição diagnóstica do ponto de vista da estrutura psíquica. Essa construção foi apresentada aos profissionais da escola, juntamente com as propostas de intervenção pensadas para cada caso levando-se em conta as particularidades do sujeito. Para um aluno, por exemplo, foi proposta uma oficina de alfabetização que utilizasse, como suporte didático, cartas de amor. 
Para outro, cujo estudo de caso evidenciou a presença do delírio, o encaminhamento proposto, de início, foi a adequação da medicação ao quadro (o aluno fazia uso apenas de tranquilizantes), para tornar possível sua permanência na escola. Dada a impossibilidade de expor, nesse trabalho, os resultados relativos a todos os casos estudados durante o desenvolvimento do

projeto, optou-se por apresentar de maneira detalhada apenas um deles, para demonstrar a metodologia empregada.

\section{ESTUDO DE CASO}

Um dos casos estudados no decurso do desenvolvimento desse projeto foi o de uma menina de 13 anos de idade - no momento da realização do diagnostico, que será designada, aqui, pelo nome de Lu. Ela era uma aluna repetente, assídua, e constituía um enigma para a equipe pedagógica. Nenhum professor tinha conseguido, desde seu ingresso na escola, há mais de seis anos, realizar uma avaliação pedagógica da mesma. Isso se devia, sobretudo, ao fato de ela não falar. Contrariando essa constatação, a mãe da criança afirmava que, em casa, ela falava normalmente. Um outro ponto levantado como dificuldade para avaliar a aluna, era o fato de Lu sempre apresentar o dever de casa completo e feito corretamente.

Em contrapartida, na escola, não atendia a nenhuma solicitação de seu professor e não respondia a nenhuma demanda que the era dirigida. Por isso, suspeitava-se de que a irmã mais velha the ajudasse na realização dos deveres. Do primeiro perfil dessa aluna, estabelecido a partir daquilo que os profissionais da escola diziam a seu respeito, destacaram-se esses elementos e a hipótese de um quadro de autismo. Em definitivo, o que identificava Lu, na escola, era o ser muda e doida, sendo inclusive chamada pelos colegas de "mudinha" e "doidinha". A leitura dos dados registrados nos prontuários escolar e psiquiátrico permitiu a elaboração da seguinte sequencia diacrítica relativo a história de Lu:

- 1988 - Nascimento de Lu. 
- 1993 - Internação em decorrência de nefrite, anemia e gastroenterite (complicações devido a um quadro grave de desnutrição).

- 1993 - A mãe nota o comportamento estranho da filha: irritabilidade e pouca comunicação com os familiares.

- 1994 - Frequenta a pré-escola durante um ano e três meses, mas não aprende nada.

- A professora observa que Lu não acompanhava a turma nas atividades, nem nas brincadeiras, não fala nada com ela, nem com os colegas, apanha sem reagir e não chora quando agredida. Nessa época, os educadores sugeriram a mãe procurar um médico para avaliar a filha.

- 1995 - Primeira consulta psiquiátrica e fonoaudiológica, no CPP - Centro Psicopedagógico: Lu mostra-se muito agitada, se contorce na cadeira, apresenta tiques nervosos e não pronuncia nenhuma palavra. Indicação diagnóstica: "Psicose infantil?"

- 1996 - Registra-se no prontuário: "contato difícil e a presença do outro torna-se ameaçadora para a criança". Indicação diagnóstica: "Debilidade mental? Autismo?"

Os elementos fornecidos a partir da entrevista com a mãe de Lu - Júlia - permitiram a seguinte construção: D. Júlia é separada do marido e cria os quatro filhos com o fruto de seu trabalho e o apoio da igreja. Lu é a filha caçula. As circunstâncias do romance familiar, nesse caso, chamam a atenção. A primeira vez que D. Júlia viu aquele que se tomou seu marido foi em uma igreja. Este, encontrava-se alcoolizado e semiconsciente, debruçado sobre o banco de uma igreja situada no Centro da cidade, onde D. Júlia ia, com frequência, fazer suas preces. Algum tempo depois, ela o reencontra em uma outra igreja, situada em um bairro. Como da outra vez, ele tinha feito uso de bebida alcoólica e encontrava-se semiconsciente.

Nesta segunda vez, aconteceu! O estado embriagado daquele homem, com ar de bonzinho, cambaleando no banco da igreja, tocou definitivamente $D$. Júlia, que se encarregou de conhecê-lo e encaminhou todo o resto do processo, até o casamento. Nunca se incomodou com o fato de ele fazer uso frequente de bebida. "Meu marido 
sempre bebeu, diz ela, mas não era de briga, não era agressivo. Apenas bebia e não falava nada." Ele era vendedor ambulante e sustentava a casa. Depois de casada, D. Júlia começou a aumentar a família, sem que isso fosse um planejamento do casal. "Eu ia tendo os filhos e ele nunca dizia nada."

Entretanto, na quarta gravidez, que veio logo após a terceira, o marido pronunciou-se a respeito, indagando "Outro?" Esse simples enunciado produziu um profundo incômodo em Júlia: mesmo encontrando-se, ainda, no primeiro mês de gestação, ela começou a sentir o feto retorcendo-se em seu ventre, sem lugar. Essa sensação durou toda a gravidez, durante a qual prevaleceu a expectativa de um aborto natural. Entretanto, o bebê vingou e nasceu no tempo certo. Nasce, então, Lu, segundo Júlia, seu bebê mais formoso.

Lu desenvolvia-se normalmente, até o dia em que seu pai tece uma segunda consideração, dizendo a esposa: "Já não está na hora de desmamar essa menina?" Pela segunda vez, um enunciado do marido deixa $D$. Júlia profundamente incomodada. Ela decide, então, jogar fora todas as mamadeiras e chupetas de Lu. $\mathrm{Na}$ noite daquele mesmo dia, diz para a filha: "A partir de hoje, não tem mais mamadeira, porque seu pai não quer." Lu estava com pouco menos de dois anos.

Segundo o relato de Júlia, a filha aceitou esse desmame abrupto sem fazer objeção, mas, a partir do dia seguinte, passou a recusar determinantemente o alimento sólido. Esse problema foi remediado com a compra de novas mamadeiras. Durante os três anos seguintes, Lu é alimentada apenas por meio da mamadeira, desenvolvendo, pouco a pouco, um quadro grave de desnutrição, que culminou em sua internação.

A irritabilidade e a falta de comunicação com os familiares vão caracterizar o comportamento de Lu, após o período de internação, que durou alguns meses. Ela passa, também, a apresentar medo, diante de qualquer pessoa vestida com roupa branca ou de jaleco, que é uma das reações características do quadro de hospitalismo. Nessa ocasião, Júlia Ihe diz: "Você não quer voltar para o hospital, não é mesmo? Para não voltar, tem que comer tudo direitinho." Lu deixa-se alimentar, mas 
seu comportamento agrava-se a ponto de os clínicos recomendarem a escola de ensino especial.

Essa história de Lu foi apresentada aos professores que trabalhavam diretamente com ela. Destacou-se o comentário despretensioso do bom marido embriagado, que, sem sombra de dúvida, interferiu no lugar de desejo reservado pela mãe a seu quarto bebe. A posição desta última pode ser comparada a das filhas de Lot, do texto Bíblico, que visando garantir a procriação da espécie humana, embriagaram o pai para que este, inconsciente, as fecundasse. A resposta que sobrevém ao comentário do marido e um sentimento de estranheza que recai sobre o feto, associado a ideia de que esse não mais encontrava lugar em seu ventre e no mundo.

Em um segundo tempo (T2), um outro comentário do marido - desta vez a respeito do desmame -, confere significação ao que teria ocorrido no início da gravidez (T1). A mãe entende que é preciso introduzir uma separação radical para o bebe. Assim, ao desmame, que, mais cedo ou mais tarde, ocorre para todo sujeito, se vincula um sentido que foi inicializado pelo marido a respeito da relação da mãe com sua prole. O sujeito responde com uma anorexia, que não apenas é uma recusa em se deixar alimentar, mas também uma recusa do outro materno, do sentido que se encontra no campo do desejo desse Outro. Enquanto resposta do sujeito, resposta do real, esse sintoma permanece velado, ou seja, não recebe interpretação e, mais tarde, e nomeado e tratado como desnutrição.

A entrevista com a mãe explicita o enigma da fala. Na verdade, em casa, Lu também não falava, apenas pronunciava alguns sons sem significado, no momento em que ouvia discos com música da igreja: "Falar ela fala, mas, nesses momentos, ela fala inglês." As observações feitas nas salas de aula e durante o horário do intervalo, evidenciaram a preocupação de Lu com o limite de seu corpo. Ela assentava-se em um canto da sala, perto da estante e quando alguém se aproximava, para pegar um livro, por exemplo, ela se encolhia, curvava-se e usava os bravos para se fechar em espiral, como se a mão estendida em sua direção pudesse penetrar o seu corpo. 
No momento da recreação, geralmente ficava sozinha, recostada no muro, escondendo se atrás dos longos cabelos negros, pressionando as costas contra a parede e encolhendo o ventre, toda vez que alguma criança passava correndo perto dela. Na sala, sentava-se de frente para a porta, para vigiar quem entrava e quem saía. Tinha medo de passar pelo lado da porta. $\mathrm{Na}$ hora de deixar a sala, ficava ansiosa, insegura. Um dia a professora estendeu-lhe a mão, para ajudá-la a franquear esse limite. Depois disso, ela sempre aguardava essa ajuda. Foi ressaltada a importância desse contato de Lu com a professora, ao que essa professora indaga: "Nossa, que responsabilidade! O que devo fazer?" ao que Ihe foi respondido: "Não faça nada diferente. Apenas permita que ela faça."

Após essa apresentação, a mudança progressiva de Lu na Escola surpreendeu a todos. "Antes ela se representava, na sala de aula, como um pontinho no canto de uma folha. Recentemente fez um desenho representando-se a si mesma como um bebê, em um berço, tomando várias mamadeiras. Lembrei-me de sua história", disse a professora. "Antes, escondia-se de todos. Agora, quando pego para fazerem algo, ela é a primeira a querer mostrar. Levanta o caderno e faz grunhidos até eu falar do exercício dela." Esses dois testemunhos exemplificam, a nosso ver, a invenção possível, na sala de aula, a partir da introdução de alguns elementos da subjetividade dos alunos difíceis.

\section{CONSIDERAÇÕES FINAIS}

Os efeitos terapêuticos dessa experiência sobre a aluna e as mudanças apresentadas por ela no campo das atividades pedagógicas levou a professora a procurar a orientadora educacional para discutir a viabilidade de um trabalho educativo, que, inicialmente, encaixasse em suspenso o propósito da alfabetização. Essa proposta já tinha sido idealizada, mas nunca posta em prática. Assim, constituíram uma turma de mocinhas, em que o atraso escolar não era mais o que identificava os elementos do grupo e, sim, o que se pode localizar como desejo das alunas. O que poderia interessar a essas adolescentes, entre 12 e 14 anos, que, como Lu, cursavam a escola há muitos anos e não tinham sido alfabetizadas? Esta foi a primeira pergunta colocada para a turma no primeiro dia de aula. Elas escolheram aprender a pintar as unhas, 
conhecer os produtos para cabelo e falar de moda. Começaram a chamar uma as outras por apelidos: burra, anta, peito grande"... "Mudinha" era o apelido de Lu.

A professora chamou atenção das meninas para esses apelidos. Contou-lhes que, quando era aluna, era chamada de Olivia Palito - porque era muito magra - e não gostava disso. Disse também que elas faziam parte de uma nova turma que havia conseguido progressos na aprendizagem e, portanto, deveriam encontrar outras formas de se tratarem, outras alternativas identificadoras que fizessem valer a proposta do grupo de ser uma turma de mocinhas. As atividades desenvolvidas pela turma incluíam passeios no entorno da escola para observação daquilo que thes pudesse interessar enquanto mocinhas. Em um desses passeios, ao avistarem rapazes em uma praça pública as alunas assoviaram para eles lançando gracejos. Tal fato envergonhou a professora que decidiu retornar imediatamente a escola e discutir com elas a adequação do comportamento do grupo, tendo em vista a nova identidade que buscavam construir.

Em sua intervenção nesse sentido dizia as alunas: "Assim não dá, porque eu sou casada e não vou sair por aí com meninas que cantam os homens na rua." Pode-se notar nos tipos de comentários que a professora passa a fazer com essa turma, a introdução de elementos de sua própria subjetividade, característica dificilmente observada, antes, em seu trabalho didático na sala de aula. Em uma das diversas excursões fora da escola a turma observou com grande interesse aulas de dança do ventre em uma academia. $O$ contato entre a professora do grupo e a professora de dança resultou na oferta de aulas gratuitas para o grupo que, inicialmente, recuou, por medo, mas, em seguida, aceitou.

Embora essa oportunidade tenha sido uma contingencia, a partir da oferta de uma pessoa que não possuía nenhuma ligação institucional com aquele grupo de alunas, acabou por se constituir o motor do desejo de aprender e permitiu desencadeamento do processo de alfabetização: inicialmente, as alunas manifestaram um vivo interesse em aprender os números para marcarem os tempos da dança, Posteriormente, em função da apresentação pública que iriam fazer, desejaram aprender a ler e escrever o próprio nome e o da professora para poder lê-los nos cartazes de divulgação. 
Durante todo esse processo Lu foi acolhida e ajudada pelas colegas, e respondia a isso demonstrando ter adquirido a possibilidade de incluir outras pessoas em seu relacionamento, sem pânico.

Conclui-se que é possível, com a metodologia proposta, aumentar a conscientização do aluno a respeito do tema, fornecer-Ihe ferramentas para identificar e valorizar suas oportunidades e qualidades, e, fundamentalmente, podemos encorajar pessoas a acreditarem em seu potencial, a sonhar alto e realizar sonhos. Por isso, este trabalho é destinado aos profissionais dos novos tempos, que tenham compromisso tirar esses alunos da margem ao qual vivem, inserindo-o, efetivamente, no ambiente escolar, para que esses tenham coragem de assumir riscos e que não tenham medo de transformar os sonhos em realidade.

\section{REFERENCIAS}

E. DUMAS, Jean. Psicopatologia da Infância e da Adolescência, Artmed, 2011.

GURSKI, Rose; DEBIEUX ROSA, Miriam; POLI; Maria Cristina. Debates Sobre a Adolescência Contemporânea e o Laço Social, Juruá, 2012.

GUTIERRA, Beatriz Cauduro Cruz; Adolescência, Psicanálise e Educação- 0 Mestre Possível de Adolescentes; Avercamp, 2003.

HABIGZANG, Luísa Fernanda; DINIZ, Eva; KOLLER, Silvia; Trabalhando com Adolescentes- Teoria e Intervenção Psicologica, Artmed, 2014.

LEVISKY, David Léo; Adolescência Reflexões Psicanalíticas, Zagodoni, 2013.

MURATORI, Filippo; Jovens Violentos- Quem são, o que Pensam, Como Ajudálos? Paulinas, 2007.

RAPPAPORT, Clara Regina; Adolescência: Abordagem Psicanalítica; Epu, 1993.

Enviado: Janeiro, 2019 
Aprovado: Maio, 2019 